\title{
The Efficiency and Degree of Penetrability of Frequent Washing Solutions Used in Endodontal Treatment
}

\begin{abstract}
ALEXANDRU ANDREI ILIESCU1', ANCA MELIAN2*, IONEL DAN - CRISTIAN³, CRISTINA STEFANESCU3 ${ }^{3}$, DIANA MARIA ANTON³, GABRIELA POPA ${ }^{3}$, MIHAELA SALCEANU2*, CRISTINA IORDACHE², MARIUS MANOLE ${ }^{4}$

University of Medicine and Pharmacy, Faculty of Dental Medecine, 66, 1 Mai Str., 200638, Craiova , Romania

${ }^{2}$ Grigore T. Popa University of Medicine and Pharmacy, Faculty of Dental Medecine,16 Universitatii Str., 700115, Iasi, Romania 3Dunarea de Jos University of Galati, Medicine and Pharmacy Faculty, Departament of Dentistry, 47 Domneasca Str., 800008 , Galati, Romania

${ }^{4}$ Iuliu Hatieganu University of Medicine and Pharmacy, Faculty of Dental Medicine, 4 Louis Pasteur Str., 400349, Cluj Napoca, Romania

The new directions of contemporary endodontics to the evolution of treatment techniques are: CTCB, digital radiography, operating microscope, apex locators, titanium nickel rotation tools and rotating systems that allow them to be used, special endodontic irrigation means, use of ultrasonic means, laser applications. The success rate of nowadays endodontic treatments based on the principles accepted and adopted so far should be rather high. However, there are studies that indicate a fairly low percentage of fully successful endodontic treatments. The main causes for which these data are recorded are various, some are strictly the dentist's technique and some are related to the patient's field. Obviously, there is a contradiction between what can be achieved and the final result. The study includes a batch of 52 teeth pluriradicular as well as monoradiculars considered irrecoverable and extracted due to clinical situations requiring this method of treatment. Anatomy of dental canals is an important factor to be considered in the irrigation efficiency of the apical region; the degree of permeability of dentinal canals in this area is poor due to very small diameters, cumulative factors can lead for sure to a failure of endodontic treatment. In the coronal and media regions of the channels, the effectiveness of the lavage solutions used could be assessed. These very good results were in accordance with the studies performed and presented.
\end{abstract}

Keywords: endodontic irrigation, endodontic treatments, channeling.

A key stage in the success of canal treatment is irrigation. The importance of this step is given by the type of irrigant used; it has the advantage of reducing friction between instruments and dentin, increasing the efficiency of needles in channeling, dissolving tissues, instrument and tooth cooling, cleaning, and antimicrobial and antibiotic effects. It should also be borne in mind that, at present, endodontic lavage becomes the only solution that can reach those areas of the root canal that can not be penetrated by any mechanical instrument [1,2].

The evolution of endodontic practice adjusted by stateof-the-arttechnology, optimal tools, and materials thatease the treatments has succeeded in creating an appropriate access of the irrigants to the entire endodontic space. Most current studies state that by strictly manual instrumentation, it is not possible to fully penetrate all endodontic channels. Rotational and ultrasonic activation of lavatory solutions have proven to be more effective[3,4].

It has been shown that bacteria and their products are the first to be accused of failure of canal treatments, playing an important role in the development and perpetuation of pulp and periapical disease. Although the bacterial root canal flora is predominantly anaerobic, Enterococcus faecalis strains have also been shown to be directly involved in the persistence of the infection influencing the prognosis of canal treatment (Engström 1964). Once the bacterium has been established in the root canal, it can no longer be eradicated by the host defense mechanism. Therefore, endodontic infections are treated by mechanical procedures aided by chemicals.

Microorganisms cause all pathology of dental pulp and periodontal tissue. To effectively treat endodontic infections, the clinician needs to know the cause and effect of the microbial invasion of the endodontic space. As soon as bacterial invasion takes place in pulp tissue, nonspecific inflammation and specific host immune response have a profound effect on disease progression. Knowledge of endogenous disease associated microorganisms is necessary to develop a basic understanding of the disease process and the success of an effective treatment against it.Although most studies have summoned bacteria in the development of endopathy, ithas recently been discovered that there are strains of viruses and fungi associated with it [5-7].

Up to these conclusions, various theories were taking place among the researchers in the field, and the most common was the Focal Infection theory.

Diversity of microorganisms din the endodontic space is very high. In the oral cavity there are 1000 species of bacteria, whereas in the case of apical periodontitis in the endodontic space, researchers in the field have found no less than 400 different bacterial species. The number increases even more in the case of recurrences of pulpitis and periodontitis, in which cases the endodontic restorations are required. It is important to mention in posttreatment diseases, in addition to bacteria, microorganisms and fungi, the emergence of new bacteria such as Archaea (grouping microorganisms with prokaryotic cellular organization, formerly framed among bacteria, are now in the field of ARCHAEA organisms which at molecular level are more similar to eukaryotes than to bacteria.) The ability of microorganisms in the endodontic space to produce biofilm and from it to endodontic infections is well known. Treated or not, apical periodontitis are certainly the product of the endodontic biofim. Among the most well-known microorganisms that inhabit biofilm are E. faecalis, which

*email: meliananca@yahoo.com Phone:0757781888; salceanu.mihaela@yahoo.com Phone:0744588269 
is part of the gram-positive coci family, optionally anaerobic, which is strongly associated with endodontic infections. Being an opportunistic pathogen agent, it causes nosocomial infections and is frequently isolated in root canals subjected to re-treatment. The ability of $E$. faecalis to form biofilm is advantageous in certain situations.

The success of endodontic treatment depends on the eradication of microbes (if present) from the root canal system and the prevention of reinfection. The root canal is molded with hand tools and rotating under constant irrigation to remove the inflamed and necrotic tissue, microbes / biofilms and other debris from the root canal space. The main purpose of the instruments is to facilitate irrigation, disinfection, and sealing. Several studies using advanced techniques such as computerized tomography (CT) have demonstrated that the prominently large areas of the root canal wall remain untouched by instruments, underlining the importance of chemical means of cleansing and disinfecting all root canal areas[8-21]. The sodium hypochlorite is currently the most used irrigant due to its properties: it performs bacterial cytotoxicity, dissolves organic matter and lubricates the channels. Even though this irrigant is widespread in endodontic practice, it remains important to note that its use to completely clean the instrumental channels is sufficient only in combination with other lavage solutions or with an efficient technique of irrigation and this is due to its surface tension. J ust like $\mathrm{NaOCl}$, the effectiveness of EDTA depends on the concentration and the length of time it is in contact with the walls of the channel. The removal of residual debris with EDTA can be achieved at a concentration of $17 \%$ agent.

The aim of this paper is to evaluate the efficacy and permeability of endodontic lavage solutions commonly used in the dental office to optimize the management of both the final seal of the channels and of the entire endodontic treatment.

\section{Experimental part}

\section{Material and method}

The study includes a batch of 52 teeth both pluri and monoradicular considered irrecoverable and extracted due to clinical situations requiring this method of treatment. 31 patients dispensarized in two private dental offices in Galati were diagnosed with chronic marginal parodontopathy, showing grade III mobility between 2016-2018.

\section{Results and discussions}

After the extractions, the teeth were washed and kept in physiological saline. Before starting the protocol for this study, the teeth were placed in the autoclave for sterilization for 40 minutes at $120^{\circ} \mathrm{C}$. This process has ensured effective destruction of all types of microorganisms and viruses to prevent the spread of infections. The teeth were distributed over 3 batches: control group - $\mathrm{NaCl}-18$ teeth - 30 channels; EDTA lot - 18 teeth - 30 channels, $\mathrm{NaOCl}$ group 17 teeth - 30 channels (table 1, fig. 1).

Table 1

GROUP/BATCH DISTRIBUTION ACCORDING TO THE TOOTH

\begin{tabular}{|c|c|c|}
\hline WASHING SOLUTIONS & Monoradicular & Polyradicular \\
\hline $\mathrm{NaCl} 0.9 \%$ & tooth & tooth \\
EDTA 17\% & 9 & 8 \\
$\mathrm{NaOCl} 2 \%$ & 10 & 8 \\
& 8 & 9 \\
\hline
\end{tabular}

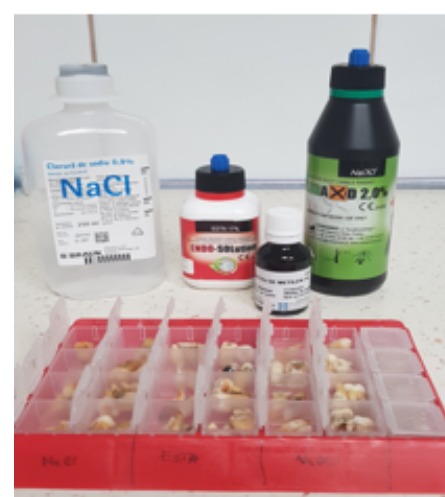

Fig.1. Preparation of the appropriate lavage solutions for each batch

Atter the batching was established, each tooth was approached according to the following protocol: the turbine access cavity was created, the contents of the pulp chamber and the root canal were removed, the permeability of Kerr needles was checked. 8, 10, 15 and 20 , and the working length on each channel was determined.

On the control lot, $0.9 \%$ sodium chloride was used in manual channeling and the step-back method was used as instrumentation technique. This batch was selected to observe exactly the differences between a treatment in which we use lavage solutions and one in which they are not used. Thus, you can see in detail how dentine reacts under different irrigation solutions.

The root canals that were used as EDTA and $\mathrm{NaOCl}$ lavage solutions were rotated with the Twisted Files system, and as instrumentation technique, they were crown-down to a .04 taper, the channels being widened to a level of 25 .

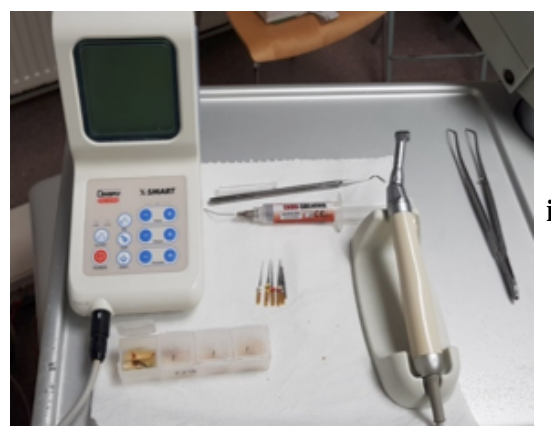

Fig. 2. Rotative instrumentation of teeth batcht prepared with EDTA 17\%

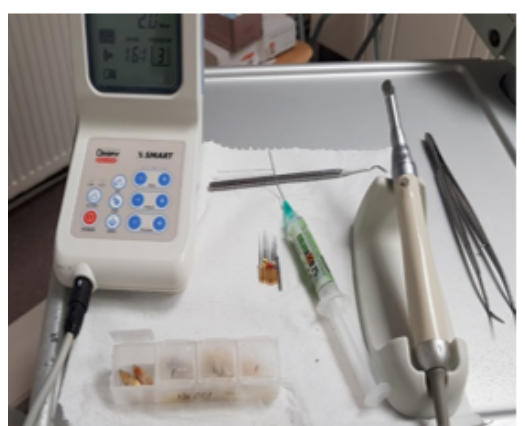

Fig.3. Rotational instrumentation of teeth prepared with $\mathrm{NaOCl} 2 \%$

On the teeth batch we used as an EDTA lavage solution, we used the ENDO-solution product, 17\% EDTA (fig. 2).

On the teeth group using sodium hypochlorite as a lavage solution, 2\% Chloraxid - Cerkamed was used. On the teeth in the two test batches of lavage solutions, EDTA and $\mathrm{NaOCl}$, at the end of the preparation, the irrigant corresponding to each batch for the final lavage was introduced. They were ultrasonically activated by means of a Miller-inserted needle inserted into the canal and the detonation probe, maintained actively for 10-30 s (fig. 3).

After this protocol, the teeth were dried, kept for $24 \mathrm{~h}$, after which $1 \%$ blue methylene was introduced into the channel (table 2). This solution was chosen as a marker to 
Table 2

LAVAGE PROTOCOL

\begin{tabular}{|l|l|}
\hline LOT & \multicolumn{1}{|c|}{ PROTOCOL } \\
\hline $\mathrm{NaCl}$ & $\begin{array}{l}\text {-2.5 } \mathrm{mL} \text { of } 0.9 \% \mathrm{NaCl} \text { was used at each instrument } \\
\text { change. } \\
-2.5 \mathrm{~mL} \text { of } 0.9 \% \mathrm{NaCl} \text { for } 3 \text { minutes at the end of root } \\
\text { canal preparation }\end{array}$ \\
EDTA & $\begin{array}{l}-2.5 \mathrm{mlof} 17 \% \mathrm{EDTA} \text { solution was used at each } \\
\text { instrument change. } \\
-2.5 \mathrm{~mL} \text { of } 17 \% \mathrm{EDTA} \text { solution was used at the end of } \\
\text { root canal preparation } \\
-2.5 \mathrm{~mL} \text { of } 17 \% \text { the ultrasonic lavage EDTA } \\
\mathrm{NaOCl} \\
-2.5 \mathrm{~mL} \text { of } 2 \% \mathrm{NaOCl} \text { solution was used to change each } \\
\text { instrument. } \\
-2.5 \mathrm{~mL} \text { of } 2 \% \mathrm{NaOCl} \text { solution was used at the end of } \\
\text { the root canal preparation. } \\
-2.5 \mathrm{~mL} \text { of } 2 \% \mathrm{NaOCl} \text { solution was used for the } \\
\text { ultrasonic final lavage. }\end{array}$ \\
\hline
\end{tabular}

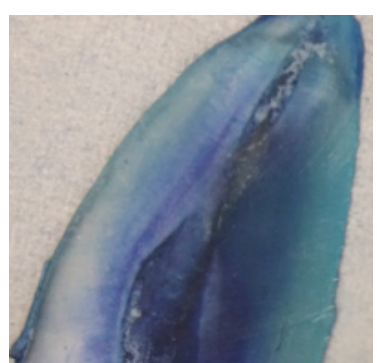

Fig 4. Monoradicular tooth from the $\mathrm{NaCl}$ control group

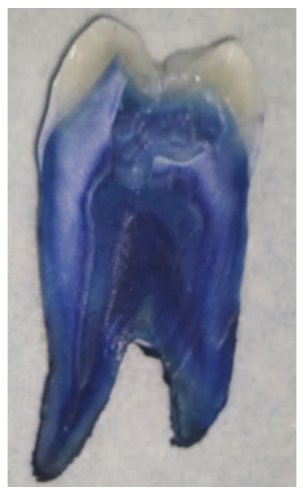

Fig.6. Polyradicular tooth from the $\mathrm{NaOCl} 2 \%$ lot

highlight the degree of penetration of the lavage solutions. All of the teeth were maintained $72 \mathrm{~h}$ after which they were longitudinally cut by means of a diamond disk 350D, $22 \mathrm{~mm}$, thickness 0.45 mounted on the microengine. This allowed the exposure of the rootcanals to be photographed and analyzed. The photos were made using an endodontic microscope at a $0.8 \mathrm{~mm}$ and $1.2 \mathrm{~mm}$ magnification (fig. 46). were also confirmed by the descriptive statistical tests both on the channel group using the 17\% EDTA solution
Fig.7. Measuring infiltrated dentine at the average $1 / 3$ using Image J

Fig.8.The dye infiltrations along the root canal

Thus, the final results were obtained by a ratio of the dentine infiltrated by dye to the total measured dentine, these being expressed as a percentage (fig. 7, 8).

The dye infiltrations along the root canal have been assessed by analyzing the interface between the channel's parietal dentine and the degree of penetration at the dental channel of the lavage solutions. The programme allowed dimensional determinations and comparisons between different infiltrations of lavage solutions on each lot, both of research and control.

The measurements were performed at the coronary level (1/3 coronary), medium (1/3 average), apical (1/3 apical). Of the total of 52 teeth, the distribution according to their type, monoradicular or pluriradicular, had a relatively equal weight, 27 being monoradicular and 25 pluriradicular. They were distributed on batches, adding up to 30 channels for each lavage solution. Although the number of channels distributed to each batch was equal, it was not possible to divide them into a number of evenly distributed teeth in turn. The results obtained with regard to the degree of penetration of the lavage solutions used were statistically analyzed to determine the differences in permissible infiltrations. The Kruskal-Wallis test was used for these determinations, after which the Dunn test was applied to highlight the statistical significance of the recorded differences. Significance level for all statistical tests was $p$ $<0.5$.

With these tests it was possible to rank the lavage quality made by each irrigant separately. Since the first tests, there was a greater efficacy of sodium hypochlorite at both coronary and apical levels, but the EDTA solution also had superior results in $1 / 3$ of the average. Some of these results following the determination of the differences between samples. Itcan see a net delimitation with the control group and on the $2 \%$ sodium chloride hypochlorite lot as opposed to the control group that was irrigated only with $\mathrm{NaCl} 0.9 \%$.

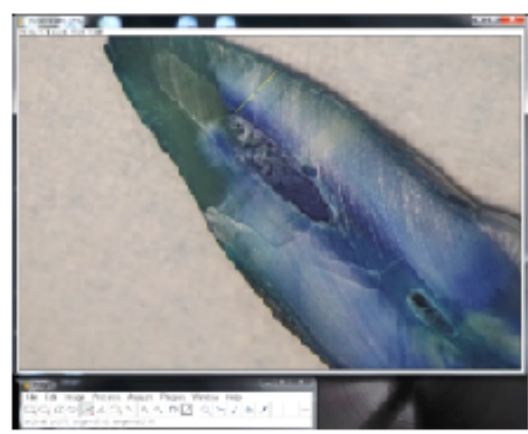
To analyze the degree of penetration of the lavage
solutions used on each batch, the Image J. programme was used. This software allowed measurements on the

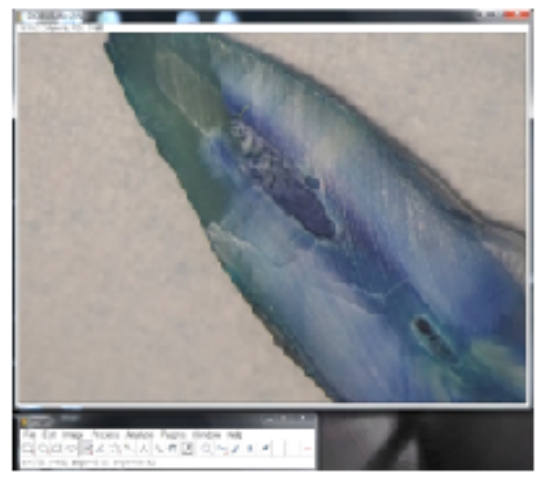

. 
In all three cases significant coronary infiltration was noted, with an average of $55.02 \% \mathrm{EDTA}$ and $54.5 \% \mathrm{NaOCl}$, which decreased along the root, averaging $50.21 \%$ EDTA and $38.10 \% \mathrm{NaOCl}$, and at the apical level $33.21 \%$ on the EDTA group, respectively $34.77 \%$ corresponding to the lot of $\mathrm{NaOCl}$.

The relatively small percentage recorded at the apical level can be based on several factors. A first cause could be the molecular structure of the Methylene Blue solution, which is likely to notbe able to penetrate the apical dentinal canal. Another cause can be attributed to the needle by which the irrigation was done, this being done during the study with a normal needle having a diameter of $0.8 \mathrm{~mm}$. This type of needles do not allow penetration across the entire length of the channel and thus apical irrigation can be compromised. This factor can also be complemented by insufficient channel enlargement in the apical region. According to a study by Cesar de Gregorio et al., which analyzes the penetrability of EDTA under various tests, the traditional irrigation needle has shown significant poor penetration on the lateral channels and has been strictly limited to penetration of the needle into the canal. For an overview of these results recorded on the three regions of root canals, we obtained a graphical representation using histograms. These representations were applicable to all areas of statistics.

Histogram charts show percentages of frequency distributions per value ranges recorded per batch. These histograms are actually the graphical equivalent of the frequency tables, which facilitates the tracking of specific problems that may arise. On the control group, the coronary infiltration had a higher frequency between $10-30 \%$, rarely having values above $60 \%$, the frequency for them did not exceed $1 \%$. On the EDTA irrigated channels, values between $40 \%$ and $90 \%$ have a high frequency of $9 \%, 5 \%$ and $3 \%$, respectively. A uniformity of these values was observed between these ranges. Not to be neglected, the two percentages recorded above $90 \%$, as are the $1 \%$ frequencies in the ranges of $0 \%-10 \%$ or $20 \%-30 \%$. Concerning the distribution of frequencies on the lot of the $\mathrm{NaOCl}$ lavage solution, a higher frequency can be noticed between $20 \%-40 \%$, which is $6 \%$. Two other frequencies under this percentage are recorded between $40 \%-50 \%$ and $70 \%-80 \%$, respectively. A percentage in addition to EDTA is also noticed between $90 \%-100 \%$. After the analysis of the batches distributed according to the lavage solution, an average was obtained on the type of tooth and the degree of infiltration allowed according to the root region concerned. It should be mentioned that this average was made withouttaking into account the lavage solution used, it was calculated according to the results of all the data obtained on each batch.

For an overview of what we presented with histograms, we represented these results in boxplot-type charts. These graphs graphically reflect the five values of the distribution, marking: minimum values, lower quartile - delimits the smallest $25 \%$ of the noticed values, the median - delimits $50 \%$ of the values (the half of the interval between the maximum and the minimum), the upper quartile - $25 \%$ of the noticed values, the maximum value - the highest value except the aberrant values.

This type of chart facilitated the detection of aberrant values obtained from the tests. The lowest values were recorded in the control group with respect to average infiltration, the median score of $50 \%$ of the total number of channels indicating an infiltration rate of $20 \%$. We could also see two aberrant values at the $60 \%$ limit. At the level of apical infiltration, and this chartindicates very low values irrespective of the lavage solution used. However, as in the other regions, the graphical median of half the lot values is $40 \%$. The difference between the maximum values recorded is $20 \%$ between the two irrigants, and the solution that achieves maximum value is the $\mathrm{NaOCl}$ solution, even if the upper quartile indicates a higher value of EDTA than $\mathrm{NaOCl}$.

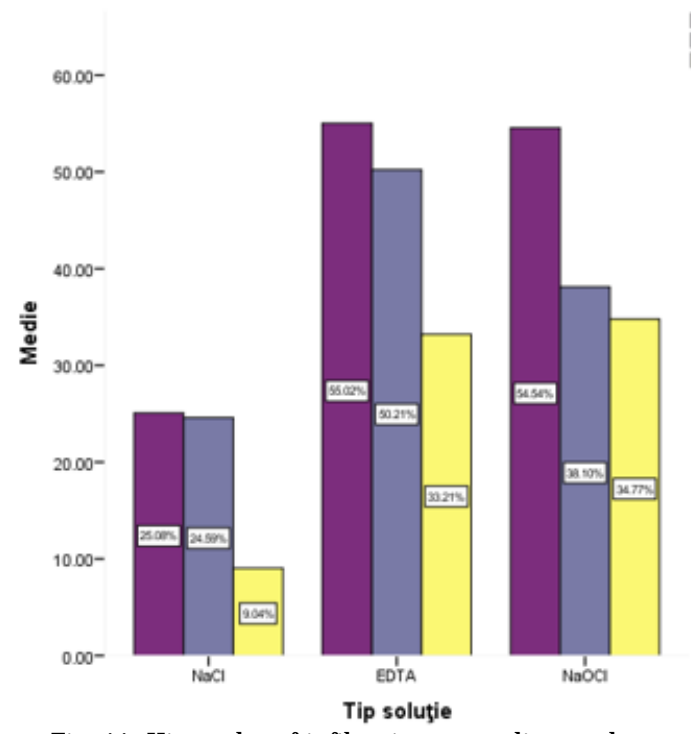

Fig. 11. Hierarchy of infiltration according to the type of lavage solution used

In a study analyzing the degree of penetrance of EDTA by Murali Mohan Thota et al it was demonstrated that the aorta has been shown to be effective in the coronary and middle canal region. They place this result on the basis of a greater number of dentinal canals, with a larger diameter in the corneal portion. Their number and diameter diminish as they advance towards the apical portion of the tooth. The authors note thatEDTA has a high degree of efficacy in removing residual debris even in the apical region, which brings a great advantage in disinfection of the entire canal. Higher surface tension of $17 \%$ EDTA may be a cause for these results. Compared to the method used for the present study, the above mentioned was adjusted by a final channel irrigation with $2.5 \% \mathrm{NaOCl}$ for 1 minute. This is probably the reason why the results obtained in the apical $1 / 3$ have been improved.

What is important to consider following this study by Murali et al., is the degree of permeability of the sealer used after EDTA irrigation of the canal. They put an important argument in favour of the irrigant by demonstrating, according to the research, a high degree of efficiency of the seal due to the use of EDTA especially in the apical area. Another study conducted in 2010 appreciates the degree of penetration of two chelating solutions: MTAD and EDTA. In these tests, the authors underwent microscopic examinations after the use of irrigants. As a method, they removed the coronal part of the tooth at the enamel-cement junction using a disk before starting the test protocol. Also, the apical region of the tooth, after having reached a Kerr 15 needle at the apical foramen, was sealed with wax to simulate natural apical contrapression. As in the previous study, hypochlorite was used at various lavage stages, and the final lavage was performed with 17\% EDTA followed by $1.3 \% \mathrm{NaOCl}$. This group achieved $80 \%$ complete removal of detritus in the coronary region and medium and $50 \%$ in the apical region and did not report the presence of large detritus. The weaker results on the apical channel region are attributed to the anatomy and the lack of penetration of the irrigants in this area. This is noted in both the previous study and the study by Vishal A. Mahajan et al. 
Richardo Machado and Lucas Fonseca Roberti Garcia published an article in 2017 about the evaluation of EDTA in removing residual debris and sealer penetration after irrigation with EDTA. This study was performed as a microscope research as this is the most accurate way of analysis. They used the $\mathrm{NaOCl}$ irrigation protocol in exchange for channel instrumentation, after which the final lavage was performed with EDTA for 3 min.

This study reveals poor infiltration in the $1 / 3$ apical channel, as well. They place this result on the limitations of an in vitro test. As in the previous study, seal penetration at the end in the apical area is much improved, on the contrary to what was already analyzed immediately after the final lavage. This confirms to a certain extent Murali's theory that the sealant is absorbed into the canal by the capillary action due to the use of chelating solutions in the endodontic lavages because they have very good results in eliminating the debris almostentirely. Concerning $\mathrm{NaOCl}$, a study by Ling Zou et al. on the penetration of sodium hypochlorite, they analyzed the infiltration rates of the solution under various lavage techniques used lately. Instead, they used the same concentration of $\mathrm{NaOCl}$ for initial irrigation: $5.25 \%$. After preparation, they were immersed in $10 \mathrm{~mL}$ of $6 \% \mathrm{NaOCl}$ solution for $5 \mathrm{~min}$ afterwards in $10 \mathrm{~mL}$ of $17 \%$ EDTA for another $5 \mathrm{~min}$. Following these protocol, the teeth were divided into groups and subjected to tests with different concentrations and temperatures of the irrigant, after which they were analyzed by microscope. They evaluated the three parameters on which the efficiency of the irrigant depended on: time, concentration, temperature. Thus, the results were obtained according to which the highest degree of penetration was $6 \% \mathrm{NaCl}$ solution exposed 20 minutes at a temperature of $45^{\circ} \mathrm{C}$. After the initial penetration in the first 2 minutes, the depth doubled in the next 18 minutes. Temperature was not such an important factor, having a minimal effect on the samples tested. The efficiency of the irrigant was dictated to its greatest extent by the concentration of the irrigant. It is also mentioned that no other irrigation technique was used in this study, apart from the classical one. The authors assert that the results would have been greatly changed if they were usedcurrent techniques, but the role of this study was to demonstrate the efficacy of $\mathrm{NaOCl}$ being the easiest way.

Unlike EDTA, NaOCl has disinfection properties and this requires an efficient working time to reach optimal potential. The ability to solubilise $\mathrm{NaOCl}$ is lost after the first 2 minutes and thus requires continuous flow of fresh irrigant introduced into the canal. Another study conducted in 2016 on $\mathrm{NaOCl}$ permeability subjected to various irrigation techniques to demonstrate that on tooth groups where activation was used ultrasonic results were satisfactory but not distinct. The highest efficiency was recorded by conventional irrigation combined with a lavage solution to remove residual debris. Activating the ultrasonic or laser irrigation did nothave the same degree of efficiency on detritus and penetrability. The authors of this study believe that classical irrigation by associating the solution of $\mathrm{NaOCl}$ with EDTA will remain the gold standard in endodontic lavage.

Prabu Mahin Szed Ismail and colleagues published in 2016 an article linking the irrigant's efficiency to new lavage techniques. Contrary to the study by Abdullah Ghorbanzadeh, they claim that the maximum penetration of the sealer used for channel obstruction was obtained following an irrigation protocol with the EndoVac system associated with ultrasound activation. The results were greatly increased, unlike the batches on which the two protocols were tested separately. It is important that the sealant can penetrate and fill those areas of the channel where there are irregularities and infiltrate the dentinal canals that the gutta percha can not penetrate by themselves. This prevents reinfusion of the canal.

The authors believe that in order for the apical region to be optimally irrigated, it is necessary to extend up to the size of the Kerr needles to be able to withstand a larger volume of irrigant. They also confirm the idea that simple, manual irrigation can easily displace debris from the apical region.

The present study was conducted to compare $\mathrm{NaOCl}$ and a chelating solution, subjecting both solutions to the same protocol to see if there is any difference in their efficacy. In the given conditions and the obstacles encountered in an in vitro study, the difference between two irrigants is not very large, did not record any significant difference. Based only on the statistics of this study, no clear judgment can be given of the more effective one to the other. Considering that what was proposed for this study, namely the degree of penetration, was measured and evaluated effectively, the efficiency of microflora and endodontic biofilm remains questionable. It is known that on endodontic biofilm, EDTA has a minimum degree of effectiveness compared to $\mathrm{NaOCl}$, but $\mathrm{NaOCl}$ does not appear to have a good result on dentinal canal without the use of EDTA. This aspect can be countered by associating the two solutions, not by mixing but simultaneously, recommending the use of the physiological serum between the two lavage sequences of these two solutions. Following these studies we can conclude that the importance of using an irrigant does not depend only by its type, but also by the technique used and the degree of concentration. Therefore, each lavage should be carried out with great care and attention to all aspects that may occur along the way. Each irrigator has its role, so it's important to know what we can use and what conditions it requires to use. The results of an endodontic treatment can be ensured by using a well-managed protocol that takes into account all factors that can intervene, thus fighting them at the right time.

\section{Conclusions}

Many studies on irrigation solutions and their role in the success of endodontic treatments have demonstrated their effectiveness in eliminating both endodontic biofilm and residual debris following root canal instrumentation.

This study aims to obtain results on two of the most used lavage solutions in the dental surgery. Based on these results, we could conclude that each has its own role and the results are consistent with the other research in the field carried out on them. What we can notice is their infiltration rate at the three regions of the canals: coronary, $1 / 3$ medium and apical. According to this study, as well as the others presented, the apical region remains an area of maximum importance and yet the most difficult to reach for complete and efficient irrigation.

\section{References}

1.FRANK SA, BARBOUR AG. Within host dynamics of antigenic variation. Infect Genet Evol. 2006, 6: 141-146.

2.HAJ HARIA, K., PAROLIA, A., SHETTY, K. V., \& MEHTA, L. K.,Biofilm in endodontics: a review. 2015, Journal of International Society of Preventive \& Community Dentistry, 5(1),

3.J HAJ HARIA, K., PAROLIA, A., SHETTY, K. V., \& MEHTA, L. K.,Biofilm in endodontics: a review. 2015, J ournal of International Society of Preventive \& Community Dentistry, 5(1),1-12. 
4.JOHN I. INGLE, DDS, MSD and J. CRAIG BAUMGARTNER, MS, DDS, PHD.Ingle's ENDODONTICS 6. Hamilton : BC Decker Inc, 2008; 221232, ISBN 978-1-55009-333-9

5.LEONARDO MR, ROSSI MA, SILVA LA, ITO IY, BONIFÁCIO KC. EM evaluation of bacterial biofilm and microorganisms on the apical external root surface of human teeth.] Endod. 2002; 28:815-8. [PubMed: 12489650].

6.MEDVEDEV AE, SABROE I, HASDAY JD, VOGEL SN. Tolerance to microbial TLR ligands: Molecular mechanisms and relevance to disease. J Endotoxin Res. 2006; 12:133-50. [PubMed: 16719986].

7.PHILIPPE SLEIMAN, DDS, DESE, Fadl Khaled, DDS, DESE, Sequence of Irrigation in Endodontics, Oral Health, May 2005.

8.ANTOHE M.,ANDRONACHE M, FEIER R, STAMATIN 0, FORNA NC, Statistical studies regarding therapeutic approaches for edentulous social clinical cases in student,,spractical stages, Romanian Journal of Oral rehabilitation, $9(2), 2017,94-99$

9. POPESCU, E., AGOP FORNA, D., EARAR, K., FORNA, N.C., Bone substitutes used in guided bone regeneration technique review, Mat. Plast., 54, no.2, 2017, p. 390-392

10.ANTOHE, M.E., AGOP FORNA, D., DASCALU, C.G., FORNA,N.C., Implications of digital image processing in the paraclinical assessment of the partially edentated patient, Rev.Chim.(Bucharest), 69, no.2,2018, p.521-524

11.CHECHERITA, L., BELDIMAN, M.A., STAMATIN ,O., et al. Aspects on structure of materials used for different types of occlusal splints. Rev.Chim.(Bucharest), 64, no.8, 2013,p.864-867

12.ANTOHE, M.E., AGOP FORNA, D., DASCALU, C.G., FORNA, N.C., The importance of observing the aesthetic requirements in partial edentulous rehabilitation - implications in medical-dental training, International Journal of education and information technologies Volume: 10 p. 199-203, 2016
13.GRADINARU, I., IGNAT ,L., DASCALU, C.G., SOROAGA, L.V., ANTOHE,M.E., Studies regarding the architectural design of various composites and nanofibres used in dental medicine, Rev.Chim.(Bucharest), 69, no.2,2018, p.328-331

14.ROMANEC, C., DOROBAT, V., ZETU, I., The autonoous patient and his competence in orthodontics practice, Revista Romana de Bioetica, 11(3), pg.66-73, 2013

15.ASAFTEI, I.V.., SANDU, I.G., MIHAIL,L., et. al., Conversion of ndustrial fedstock mainly with butanes and butenes over B-HZSM-5 and ZnHZSM-5 modifed catalysts, Rev.Chim.(Bucharest), 66, no.3, 2015, pg.336-341

16.MATEI,M.N., EARAR, K., TRINCA, L.C., Degradation characteristics of poly-tetrafluoroethylene coatings on stainlesssteel orthodontic wires immersed in tuna fish derived products, Rev. Chim. (Bucharest), 67, no. 4, 2016, p.800-807

17.ROMANEC, C., PACURAR, M., DECUSARA,M., SCUTARIU, M.M., HINGANU, D., CIUPILAN, C., Labio-palatine cleft, morphological substrate, Rev.Chim.(Bucharest), 69, no.4, 2018, p.1002-1005

18. MATEI ,M.N., CHISCOP, I., EARAR, K., et al., Evaluation of corrosion resistance of $\mathrm{NiTi} \mathrm{Nb}$ orthodontic wires in tomato juice, Rev.Chim.(Bucharest), 66, no.12,2015, p.2009-2012

19.MARECI, D., EARAR, K., ZETU, I., Comparative electrochemical behaviour, of uncoated and coated Ni Ti, for dental orthodontic wires, Rev.Chim.(Bucharest), 52, no.2, 2015, p, 150-153

20. ROMANEC, C., DRAGOMIR, B., BICA, C., The prophylactic orthodontic treatment with removable appliances in children, Rev.Chim.(Bucharest), 69, no.3,2018, p.693-696

21. MESAROS, A.S., ROMANEC, C., MESAROS, M., MOLDOVAN, M., BALDEA, I., In vitro testing of experimental and commercial bracket bonding materials, Mat. Plast., 54, no.4, p.620-625

$\overline{\text { Manuscript received: } 26.08 .2018}$ 